\title{
Double Star/Cluster observation of neutral sheet oscillations on 5 August 2004
}

\author{
T. L. Zhang ${ }^{1,4}$, R. Nakamura ${ }^{1}$, M. Volwerk ${ }^{1,6}$, A. Runov ${ }^{1}$, W. Baumjohann ${ }^{1}$, H. U. Eichelberger ${ }^{1}$, C. Carr ${ }^{2}$, \\ A. Balogh ${ }^{2}$, V. Sergeev ${ }^{3}$, J. K. Shi ${ }^{4}$, and K.-H. Fornacon ${ }^{5}$ \\ ${ }^{1}$ Space Research Institute, Austrian Academy of Sciences, 8042 Graz, Austria \\ ${ }^{2}$ Imperial College, London, UK \\ ${ }^{3}$ St. Petersburg University, Russia \\ ${ }^{4}$ Laboratory for Space Weather, Chinese Academy of Sciences, Beijing, China \\ ${ }^{5}$ Institut für Geophysik und extraterrestrische Physik, Braunschweig, Germany \\ ${ }^{6}$ Max-Planck Institut für extraterrestrische Physik, Garching, Germany
}

Received: 17 February 2005 - Revised: 8 April 2005 - Accepted: 21 April 2005 - Published: 8 November 2005

Part of Special Issue "Double Star - First Results"

\begin{abstract}
Previous Cluster observations have shown that the flapping motions of the Earth's magnetotail are of internal origin and that kink-like waves are emitted from the central part of the tail and propagate toward the tail flanks. The newly launched Double Star Program (DSP) TC-1 satellite allows us to investigate neutral sheet at $10-13 \mathrm{Re}$ in the tail. Using conjunctions with Cluster we will have simultaneous observations at $10-13$ and $16-19 \operatorname{Re}$ of these flapping motions. In this paper, we present the first results of neutral sheet oscillations observed by the Cluster and Double Star satellites on 5 August 2004.
\end{abstract}

Keywords. Magnetospheric physics (Magnetotail; Plasma sheet) - Space plasma physics (Waves and instabilities)

\section{Introduction}

Since the first discovery of the magnetotail neutral sheet (Ness, 1965), it has been found that the neutral sheet frequently appears to be in motion due to changing solar wind conditions and geomagnetic activity. Oscillations of the neutral sheet have been identified by the multiple crossings of the neutral sheet by spacecraft. These oscillations are due to flapping motions of the neutral sheet in the north-south direction (Speiser and Ness, 1967), waves traveling along the axis of the magnetotail (Speiser, 1973) or wave motion along the dawn-dusk direction (Lui et al., 1978).

It has been observed in Cluster case studies that a wave moving in the dawn-dusk direction could cause a neutral sheet very steeply inclined toward the Y-axis (Zhang et al., 2002; Sergeev et al., 2003). Further statistical studies revealed that this dawn-dusk wave is kink-like and has a pre-

Correspondence to: T. L. Zhang

(tielong.zhang@oeaw.ac.at) ferred propagation direction from the tail center to flank (Sergeev et al., 2004; Runov et al., 2005b). Thus the source of this kink-like wave is localized in the central part of the magnetotail.

Neutral sheet kink-like waves along the Y-axis have been observed at tailward distances of $\sim 15$ to 30 Re by IMP 5 (Lui et al., 1978) and around $\sim 14$ to 19 Re by Cluster (Runov et al., 2005b). In addition, Volwerk et al. (2003) found kinkmode waves along the $\mathrm{X}$-axis. However, no observation in the near-Earth neutral sheet is available. In addition, all the observations are made from a single satellite or a Cluster of closely spaced spacecraft, i.e. one single location. No simultaneously observation at two different magnetotail locations has been made to date.

The Double Star Program is the first Chinese space science mission. The mission consists of two spacecraft with orbits designed to have good conjunctions with Cluster. The first Double Star satellite, known as TC-1 (which is from the Chinese abbreviation of "Explorer 1"), was launched on 29 December 2003, into a nearly equatorial orbit with an apogee just about $13 \mathrm{R}_{E}$ and a perigee altitude of $570 \mathrm{~km}$. The second satellite, TC- 2 was launched six months later on 24 July 2004 into a polar orbit with an apogee of $7 \mathrm{R}_{E}$ ( Liu et al., 2005)

Double Star, together with Cluster, enable us to make simultaneous multi-point, multi-scale observations in many key magnetospheric regions. Using Double Star nightside conjunctions with Cluster we will have simultaneous observations at tailward distances of $10-13$ and $16-19 \mathrm{R}_{E}$. In this paper we present observations of current sheet multiple crossings on 5 August 2004. We determine the normal direction and the motion of the neutral sheet using four spacecraft and we determine the normal direction at TC-1 using minimum variance analysis. We show that the multiple crossings of the neutral sheet by the spacecraft can be attributed to a 

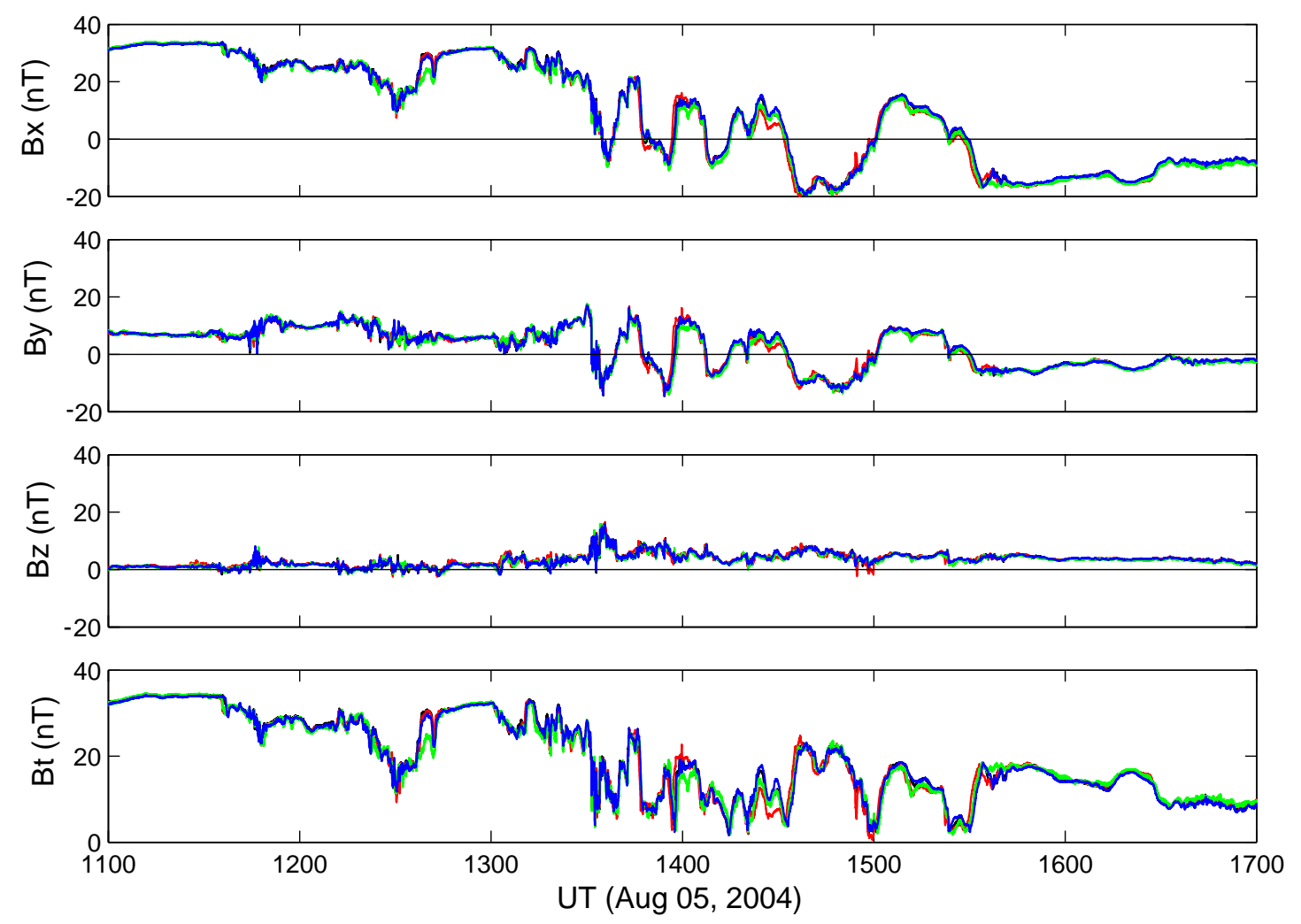

Fig. 1a. Cluster magnetic field in GSM coordinates. Note the neutral sheet crossings starting around 12:00 UT.
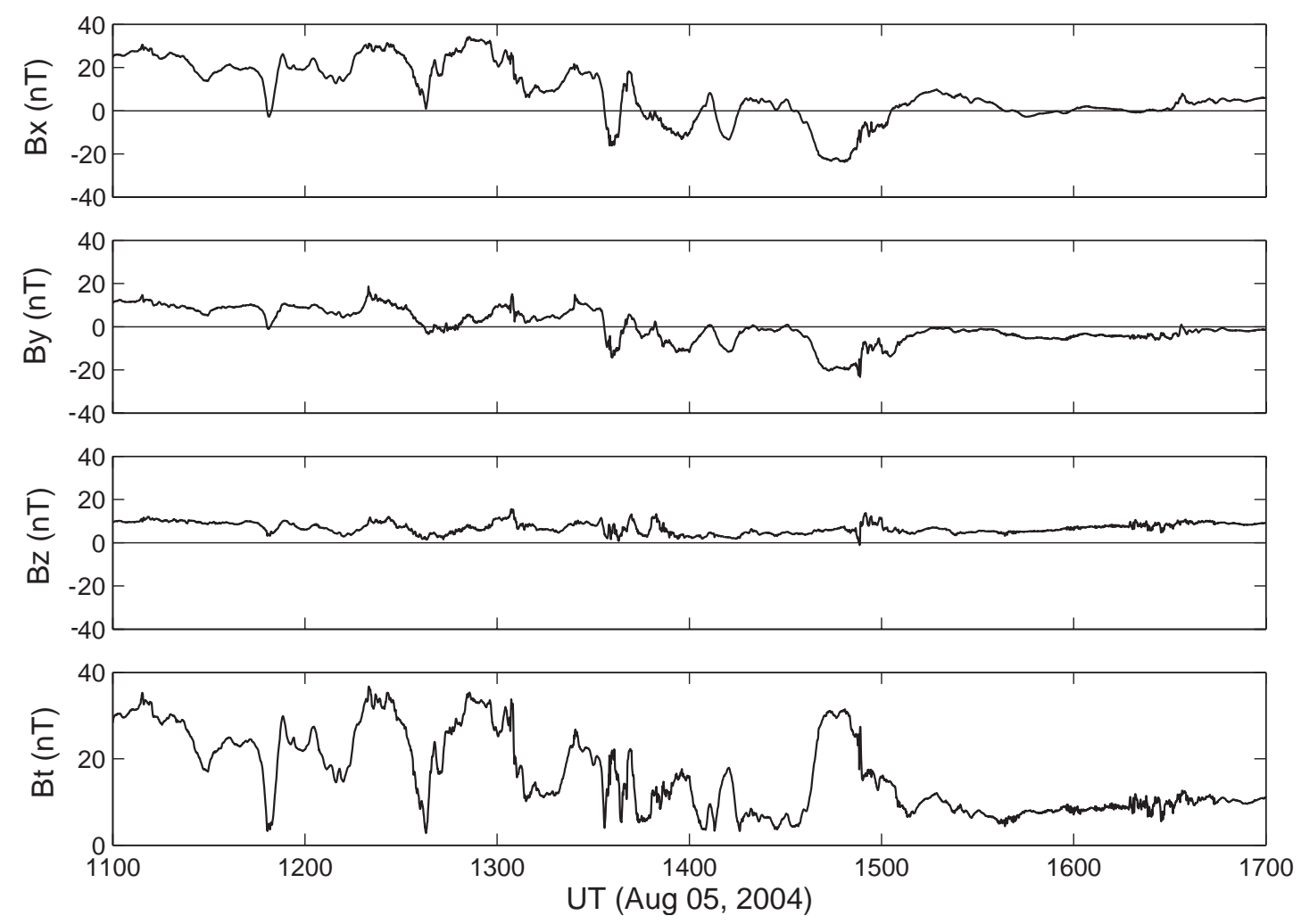

Fig. 1b. TC-1 magnetic field in GSM coordinates. 


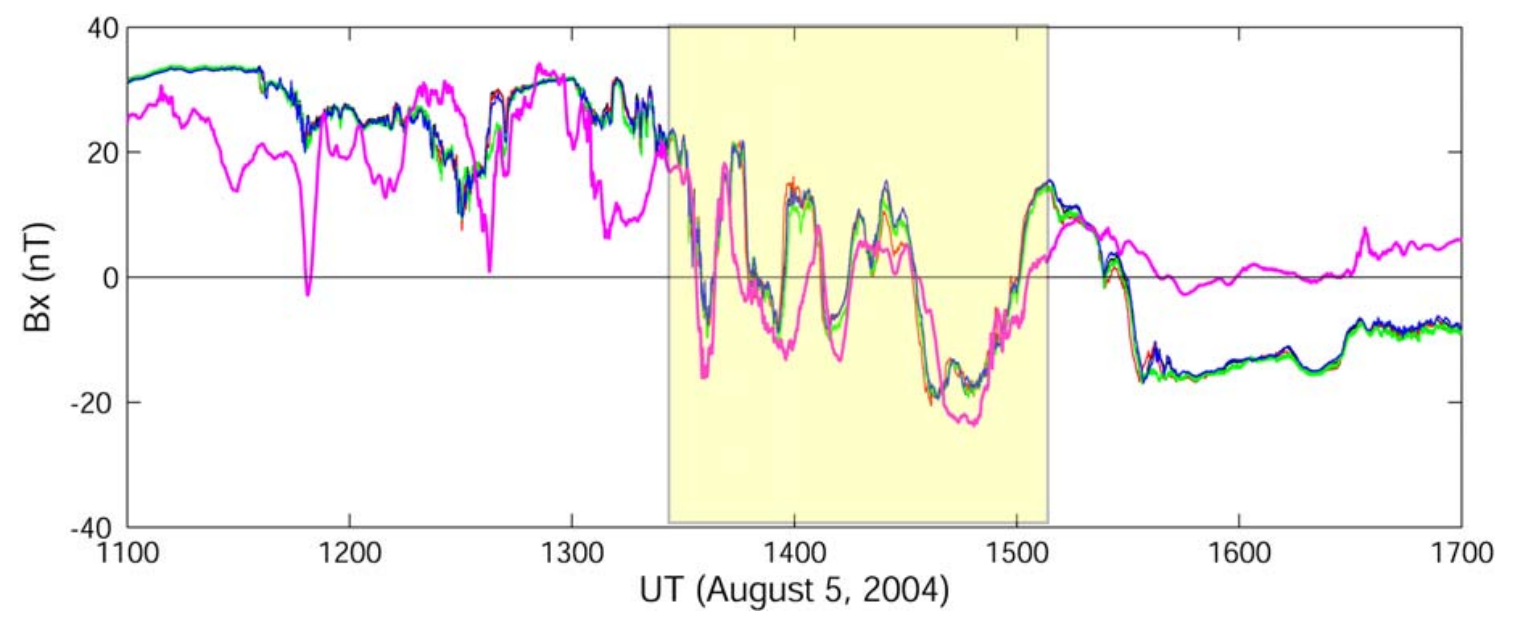

Fig. 2. Comparison of the Bx components of the magnetic field observed by Cluster and TC-1. The thick magenta line is the TC-1. The shaded region indicates the eight neutral crossings to be studied in detail.

kink wave along the dawn-dusk direction. The simultaneous observation of the wave at both Cluster and TC- 1 suggests that this kink wave is of a global nature.

\section{Observations}

Figures $1 \mathrm{a}$ and $\mathrm{b}$ show overviews of the period 11:00-17:00 on 5 August 2004, during which both the Cluster and TC-1 satellites were in the magnetotail and had multiple crossings of the neutral sheet, as indicated by the reversal of the $\mathrm{Bx}$ polarity. Figure 1a shows Cluster FGM magnetic field data at 1-s resolution (Balogh et al., 2001). The data are shown in GSM Cartesian coordinates with a color scheme of black, red, green, and blue for spacecraft 1 to 4 , respectively. In Fig. 1a, all Cluster spacecraft are located initially in the north lobe indicated by $\mathrm{Bx}>0$. Beginning with the first crossing at $\sim 13: 34$ UT, there are nine crossings of the neutral sheet in about two hours, before Cluster is finally situated in the southern hemisphere. All crossings satisfy the common definition of neutral sheet, i.e. the $\mathrm{Bx}=0$ and the magnetic field intensity reaches a minimum. The Cluster tetrahedron moves slowly in the $-\mathrm{Z}$ direction. At 13:34 UT, the time of the first crossing, Cluster s/c 1 was at GSM position of $(-15.4,-8.9$, 3.4) Re. At 15:00 UT, Cluster s/c 1 was at $(-16.1,-9.2$, 2.4).

Figure $1 \mathrm{~b}$ shows TC- 1 spin averaged magnetic field measurements with about 4-s resolution in GSM coordinate (Carr et al., 2005, this issue). The flapping motion of the neutral sheet can be identified by the multiple crossings of the $\mathrm{Bx}=0$ line. The TC- 1 spacecraft moves toward the dawnward from a GSM position of $(-11.4,-6.2,2.7)$ Re at 13:33 UT to $(-10.7,-6.8,2.6) \mathrm{Re}$ at 15:09 UT. Comparing Fig. 1a and Fig. 1b, we see that both TC-1 and Cluster spacecraft, which were sited $5 \mathrm{Re}$ apart, observed the very similar magnetic profiles with multiple neutral sheet crossings. We note that both Cluster and TC-1 were located at same local time sector. To illustrate the similarity of the magnetic profile for both TC-1 and Cluster, we show in Fig. 2 the Bx components of the magnetic field. We identify eight crossings both for TC-1 and Cluster, as shown in Fig. 2 by shaded area. As will be shown, these multiple crossings are due to the dawndusk wave propagating across the neutral sheet. Hence we will study these eight crossings in details in the following.

Using four Cluster spacecraft magnetic field measurements, we determine the neutral sheet orientation and speed along the neutral sheet normal (Zhang et al., 2002). The first crossing at 13:34 UT exhibits a motion different from the other 7 crossings, indicated both by the normal direction and speed along the normal direction. For crossing 2 to 8 , we find that all y-components of the neutral sheet normal direction are negative indicating a motion in the dawn direction with a speed about $20-50 \mathrm{~km} / \mathrm{s}$. Further we note that the sign of the z-components of the normal direction of crossings 2 to 8 switches between positive and negative in sequence, which implies a wavy profile propagating dawnward. We illustrate the motion of the neutral sheet relative to the Cluster spacecraft by plotting an apparent spacecraft trajectory crossing the neutral sheet 8 times in the Y-Z plane in Fig. 3.

To determine the normal direction of the neutral sheet for TC-1, we apply minimum variance analysis (MVA) (Sonnerup and Cahill, 1967). Table 2 shows the normal directions of the TC-1 neutral sheet crossings determined by MVA. The ratio of the intermediate to the minimum eigenvalues, $\lambda_{2} / \lambda_{3}$, is also given in this table. Overall the values of the ratio indicate that the normal are basically well defined. Furthermore, care has been taken to ensure the time stationarity of the normal direction during our MVA determination (Zhang et al., 2005). To do so, we perform MVA on nested sets of data intervals centered at the middle of the neutral sheet crossing. We find that the normal directions for all crossings in Table 2 are rather time stationary since the results from all the different nested segments are similar. From Table 2, we find that the normal direction of neutral sheet crossings clearly indicate a wave motion along the dawn-dusk direction, consistent 

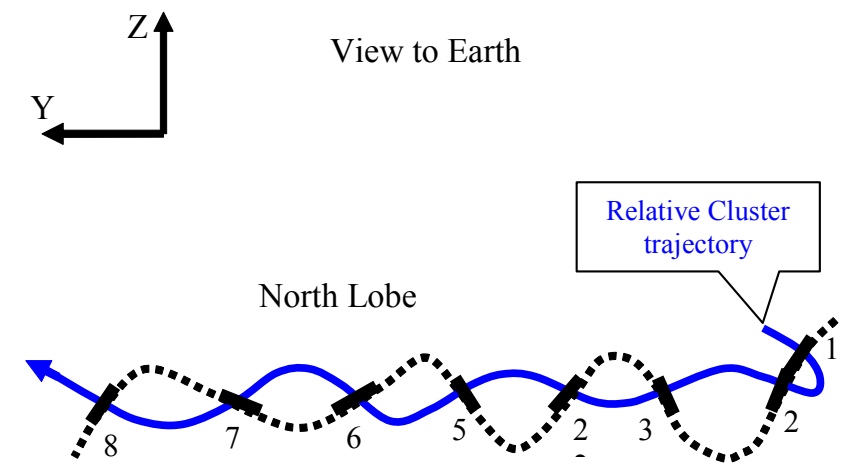

South Lobe

Fig. 3. Schematic illustration of the motion of the neutral sheet determined from each individual crossing in the GSM Y-Z plane. The thick short lines, which are connected by the dotted line, are the neutral sheet orientations determined at each crossing as listed in Table 1.

Table 1. Neutral sheet crossings on 5 August 2004 by Cluster.

\begin{tabular}{cccc}
\hline Crossing & Time & Normal direction & Speed $(\mathrm{km} / \mathrm{s})$ \\
\hline 1 & $13: 34$ & $-0.283,0.677,0.679$ & 194 \\
2 & $13: 38$ & $0.091,-0.895,-0.436$ & 57 \\
3 & $13: 47$ & $0.128,-0.931,0.342$ & 24 \\
4 & $13: 57$ & $0.483,-0.624,-0.614$ & 20 \\
5 & $14: 07$ & $0.545,-0.754,0.368$ & 38 \\
6 & $14: 14$ & $0.205,-0.302,-0.931$ & 39 \\
7 & $14: 32$ & $0.512,-0.742,0.433$ & 18 \\
8 & $15: 00$ & $0.509,-0.608,-0.610$ & 23 \\
\hline
\end{tabular}

with Cluster observation. The parameters from Table 1 and Table 2 further support the indication from Fig. 2, i.e. that a dawn-dusk propagation wave is observed simultaneously by TC-1 and Cluster on 5 August 2004.

\section{Discussion}

The magnetotail neutral sheet is best represented by an arched surface which separates magnetic field lines of opposite polarity. The magnetotail neutral sheet is anchored to the geomagnetic dipole at a hinging distance of 11 Re (Dandouras, 1988). As mentioned in the introduction, the neutral sheet kink-like wave along the Y-axis has been observed at tailward distances of $\sim 14$ to $30 \mathrm{Re}$ (Lui et al., 1978; Runov et al., 2005b). The present study shows that this wave can be observed as close to the Earth as $11 \mathrm{Re}$ along the $\mathrm{X}$ direction, in the neighbourhood of the magnetotail hinge point. In other words, the whole near-Earth magnetotail neutral sheet $(-11 \mathrm{Re}>\mathrm{X}>-30 \mathrm{Re})$ likely to oscillate in this kinklike mode, which internally produces in the central part of the tail and propagates toward the tail flanks. A schematic view of this wave is shown in Fig. 4 based on this study and
Table 2. Neutral sheet crossings on 5 August 2004 by TC-1.

\begin{tabular}{cccc}
\hline Crossing & Time & Normal direction & $\lambda_{2} / \lambda_{3}$ \\
\hline 1 & $13: 33$ & $0.676,-0.716,0.172$ & 9.4 \\
2 & $13: 38$ & $0.365,-0.817,-0.446$ & 1.7 \\
3 & $13: 45$ & $0.229,-0.609,0.759$ & 12.6 \\
4 & $14: 04$ & $0.508,-0.847,-0.155$ & 3.1 \\
5 & $14: 07$ & $0.404,-0.883,-0.239$ & 6.8 \\
6 & $14: 14$ & $0.514,-0.830,-0.216$ & 9.6 \\
7 & $14: 32$ & $0.370,-0.678,0.635$ & 1.7 \\
8 & $15: 09$ & $0.462,-0.604,-0.650$ & 5.5 \\
\hline
\end{tabular}

earlier observations (Zhang et al., 2002; Sergeev et al., 2004; Runov et al., 2005b).

In order to estimate the amplitude of this wave, we performed a detailed analysis of each Cluster neutral sheet crossing by calculating the Cluster tetrahedron barycenter transverse distance from the neutral sheet (Runov et al., 2005a). Except for the first crossing, all crossings indicate a wave amplitude between 4000 and $8000 \mathrm{~km}$ which is about the same as the statistical result of $1 \mathrm{Re}$ (Runov et al., 2005b). Further we infer that the wavelength is about 4 Re by taking a wave propagation velocity of $\sim 20 \mathrm{~km} / \mathrm{s}$ and a wave period of $\sim 20$ min estimated from Table 1 and Table 2 . Runov et al. (2005b) found statistically that the dawn-dusk wave often tilts the neutral sheet about $45 \mathrm{deg}$ and has an amplitude of $1 \mathrm{Re}$. For a simple sinusoidal wave this would be equivalent to a wavelength of $4 \mathrm{Re}$. Zhang et al. (2002) also found wavelength of $4 \mathrm{Re}$. It seems that $4 \mathrm{Re}$ represent a typical wavelength for this kind of wave.

Using magnetic field measurements from TC-1 and Cluster we find that the neutral sheet was dominated by a kinklike wave structure propagating from the central sector of the magnetotail toward dawn at tailward distances of both $11 \mathrm{Re}$ and $16 \mathrm{Re}$. Simultaneously observations at same local time by TC- 1 and Cluster have provided us a global picture of this kind of wave structure for the first time. The driving mechanism of this wave is still subject to debate (Sergeev et al., 2004) and a further study using both plasma and magnetic field data of Double Star and Cluster is underway. Nevertheless, our first result in this paper and in accompanied papers (Nakamura et al., 2005; Volwerk et al., 2005) has already demonstrated the merit of the constellation of ClusterDouble Star in helping us to understand magnetotail.

Acknowledgements. We are greatly indebted to Z. X. Liu, J. Wu, C. P. Escoubet, and B. Gramkow for the successful Double Star Program. The work at IWF is partly supported by INTAS 03-513738 grant. The work is also supported in part by the International Collaboration Research Team Program of the Chinese Academy of Sciences. The work by KHF and MV are financially supported by the German Bundesministerium für Bildung und Forschung and the Deutsches Zentrum für Luft- und Raumfahrt under contract $50 \mathrm{OC}$ 0104.

Topical Editor T. Pulkkinen thanks I. S. Dandouras and another referee for their help in evaluating this paper. 


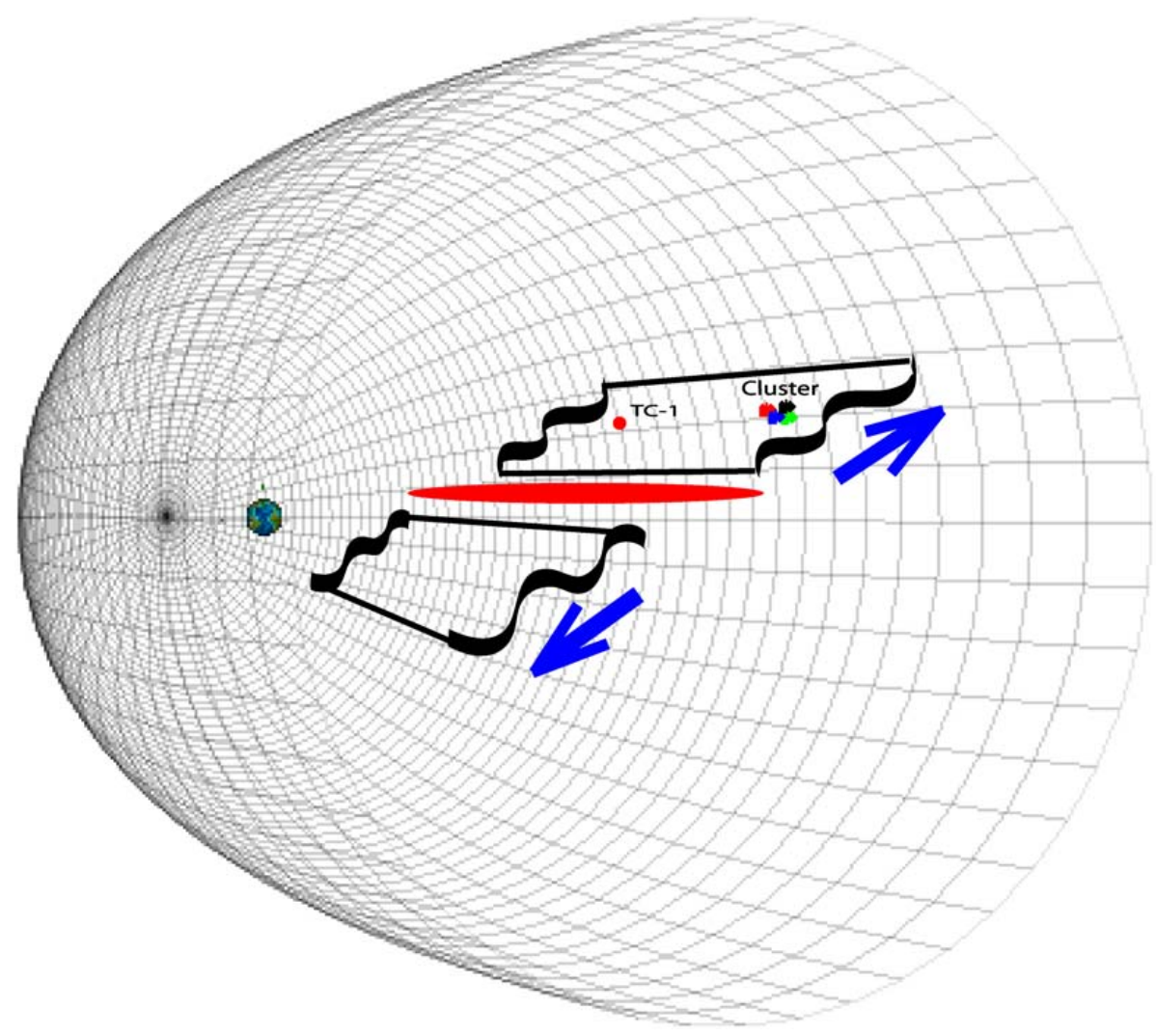

Fig. 4. Schematic view of the kink-like wave emitted from the central part of the magnetotail and propagates toward the tail flanks. The TC-1 and Cluster were located $5 \mathrm{Re}$ apart at same local time. For the first time, the wave has been observed at two different magnetotail locations simultaneously. Based on this study and earlier observations, this dawn-dusk wave can be observed at tailward distances of $\sim 11$ to 30 Re. The magnetopause envelop is produced from Orbit Visualization Tool (K. Stasiewicz, M. Khotyaintsev and Y. Khotyaintsev, http://ovt.irfu.se).

\section{References}

Balogh, A., Carr, C. M., Acuna, M. H., Dunlop, M. W., Beek, T. J., Brown, P., Fornacon, K. H., Georgescu, E., Glassmeier, K.H., Harris, J., Musmann, G., Oddy, T., and Schwingenschuh, K.: The Cluster magnetic field investigation: overview of in-flight performance and initial results, Ann. Geophys., 19, 1207-1217, 2001 ,

\section{SRef-ID: 1432-0576/ag/2001-19-1207.}

Carr, C., Brown, P., Zhang, T. L., Gloag, J., Horbury, T., Lucek, E., Magnes, W., O’Brien, H., Oddy, T., Auster, U., Austin, P., Aydogar, O., Balogh, A., Baumjohann, W., Beck, T., Eichelberger, H., Fornacon, K.-H., Georgescu, E., Glassmeier, K.-H., Ludlam, M., Nakamura, R., and Richter, I.: The Double Star magnetic field investigation: instrument design, performance and highlights of the first year's observations, Ann. Geophys., 23, 27132732, 2005.

Dandouras, J.: On the average shape and position of the geomagnetic neutral sheet and its influence on plasma sheet statistical studies, J. Geophys. Res., 93, 7345, 1988.

Liu, Z. X., Escoubet, C. P., Pu, Z., Laakso, H., Shi, J. K., Shen, C., and Hapgood, M.: The Double Star mission, Ann. Geophys., 23, 2707-2712, 2005.

Lui, A. T. Y., Meng, C.-I., and Akasofu, S.-I.: Wavy nature of the magnetotail neutral sheet, Geophys. Res. Lett., 5, 279-282, 1978.
Nakamura, R., Baumjohann, W., Zhang, T. L., Carr, C. M., Balogh, A., Fornacon, K.-H., Georgescu, E., Reme, H., Dandouras, I., Takada, T., Volwerk, M., Asano, Y., Runov, A., Eichelberger, H., Klecker, B., Mouikis, C. Kistler,, L. M., and Amm, O.: Cluster and Double Star observations of dipolarization, Ann. Geophys., 23, 2915-2920, 2005.

Ness, N. F.: The Earth's magnetic tail, J. Geophys. Res., 70, 2989, 1965.

Runov, A., Sergeev, V. A., Nakamura, R., Baumjohann, W., Zhang, T. L., Asano, Y., Volwerk, M., Vörös, Z., Balogh, A., and Reme, H.: Reconstruction of the magnetotail current sheet structure using multi-point Cluster measurements, Planet. Space Sci., 53, 237-243, 2005a.

Runov, A., Sergeev, V. A., Baumjohann, W., Nakamura, R., Apatenkov, S., Asano, Y., Volwek, M., Vörös, Z., Zhang, T. L., Petrukovich, A., Balogh, A., Sauvaud, J.-A., Klecker, B., and Reme, H.: Electric current and magnetic field geometry in flapping magnetotail current sheets, Ann. Geophys., 23, 1391-1403, 2005b,

SRef-ID: 1432-0576/ag/2005-23-1391.

Sergeev, V., Runov, A., Baumjohann, W., Nakamura, R., Zhang, T. L., Volwerk, M., Balogh, A., Reme, H., Sauvaud, J. A., Andre, M., and Klecker, B.: Current sheet flapping motion and struction observed by Cluster, Geophys. Res. Lett., 30, 1327, doi:10.1029/2002GL016500, 2003.

Sergeev, V., Runov, A., Baumjohann, W., Nakamura, R., Zhang, T. L., Balogh, A., Louarn, P., Sauvaud, J. A., and Reme, H.: Ori- 
entation and propagation of current sheet oscillations, Geophys. Res. Lett., 31, L05807, doi:10.1029/2003GL019346, 2004.

Sonnerup, B. U. Ö. and Cahill, L. J.: Magnetopause structure and attitude from Explorer 12 observations, J. Geophys. Res., 72, $171,1967$.

Speiser, T. W.: Magnetospheric current sheets, Radio Sci., 8, 973, 1973.

Speiser, T. W. and Ness, N. F.: The neutral sheet in the geomagnetic tail: Its motion, equivalent currents, and field line reconnection through it, J. Geophys. Res., 72, 131, 1967.

Volwerk, M., Zhang, T. L., Nakamura, R., Runov, A., Baumjohann, W., Glassmeier, K.-H., Takada, T., Eichelberger, H. U., Carr, C. M., Balogh, A., Klecker, B., and Rème, H.: Plasma flow channels with ULF waves observed by Cluster and Double Star, Ann. Geophys., 23, 2929-2935, 2005.
Volwerk, M., Glassmeier, K.-H., Runov, A., Baumjohann, W., Nakamura, R., Zhang, T. L., Klecker, B., Balogh, A., and Rème, H.: Kink mode oscillation of the current sheet, Geophys. Res. Lett., 30, 1320, doi:10.1029/2002GL016467, 2003.

Zhang, T. L., Baumjohann, W., Nakamura, R., Balogh, A., and Glassmeier, K.-H.: A wavy twisted neutral sheet observed by Cluster, Geophys. Res. Lett., 29, 1899, doi:10.1029/2002GL015544, 2002.

Zhang, T. L., Baumjohann, W., Nakamura, R., Volwerk, M., Runov, A., Vörös, Z., Glassmeier, K.-H., and Balogh, A.: Neutral sheet normal direction determination, Adv. Space Res., in press, vol. 36, doi:10.1016/j.asr.2004.08.010, 2005. 